\title{
Epidemiological Investigations of an Outbreak of Intestinal Atresia in Two Israeli Dairy Herds
}

\author{
Jacob BRENNER ${ }^{1)}$ and Uri ORGAD ${ }^{2)}$ \\ ${ }^{1)}$ Neonatal Diseases Prevention Unit and ${ }^{2)}$ Department of Pathology, Kimron Veterinary Institute, 50250, Bet Dagan, Israel
}

(Received 29 November 2001/Accepted 8 October 2002)

ABSTRACT. An epidemiological investigation of an outbreak of intestinal atresia in Israeli Holstein-Friesian newborn calves showed a linkage with rectal palpation for early pregnancy diagnosis, performed less than 42 days after insemination. The odds of an exposed calf, i.e., one born to a dam that was diagnosed by early palpation as having intestinal atresia were 119.7 times higher than one bor $n$ in normal control herds (95\% CI; 7.4-1946.3). A total of 682 calves-at-risk was recorded from mid-1998 to mid-2000 and a total of 47 calves $(6.9 \%)$ were born with intestinal atresia during this period. Two forms of intestinal atresia were recognized at post-mortem: atresia coli and atresia ilei.

KEY WORDS: atresia, calf.

J. Vet. Med. Sci. 65(1): 141-143, 2003

Congenital intestinal malformations occur rather frequently in cattle. There are several types, each with its own prognosis. Atresia ani and atresia recti are hereditary malformations, which occur often in calves [17], and sometimes in sheep [9]. Intestinal agenesia, hypoplasia or atresia other than those affecting the rectum is uncommon. In calves congenital intestinal atresia, which involves the ileum [7, 8, $18,19]$, is controlled by an autosomal recessive lethal factor $[9,13]$.

On the other hand, palpation of the amniotic vesicle during the period of principal organogenesis, between 36 and 42 days of gestation, has been implicated as a cause of intestinal atresia $[2,12]$.

In mid-April 1999, atresia coli was diagnosed in a newborn calf on post-mortem (PM) at the Kimron Veterinary Institute. It was subsequently reported that other calves in this herd and in another herd located $1 \mathrm{~km}$ away from the first, did not defecate and died at the age of 3-4 days. Until this time (4/1999), 23 calves that presented this clinical manifestation had been born in both herds (14 in the first and 9 in the second herd).

The dairyman had observed clear yellowish or white mucus excreted or expelled from the rectum of these calves which had not defecated during their first 3-4 days of life, until they died or were euthanized. All these calves were depressed, anorectic and suffered from abdominal distension.

At necropsy, performed by the attending veterinarian, stasis of the intestinal contents was assessed in certain parts of the intestine. This unidentified intestinal "cul-de-sac" segment appeared as a massive swelling upstream, while downstream a thin transparent cord without digested content could be observed.

These findings led us to suspect that early rectal palpation of dams (<42 days post insemination (PI)) was connected with this ongoing outbreak. We based our speculation on similar outbreaks of intestinal atresia reported by others
$[2,12]$ and on the confirmation that this practice had been adopted in these two herds approximately one year earlier.

The same practitioner worked with both herds, into which he had introduced this new diagnostic procedure. Before his arrival, pregnancy had been diagnosed in both herds by the classic method, as performed over 6 weeks PI.

At the time of our investigation (mid-1999), 350 cows had already been diagnosed by early palpation (exposed). Therefore, every new case of atresia in newborn calves during one year (till mid-2000) was documented and brought to our attention. On the basis of the characteristic clinical features and confirmation by post-mortem examination, 24 additional cases were recorded. The cases of intestinal atresia that had occurred from mid-1998 to mid-1999 $(n=23)$, were collected from the farm records, based on the attending veterinarian's confirmation. The attending veterinarian and we examined all the other cases, which were identified on the basis of the absence of defecation, on the clinical manifestation and on gross necroscopy performed by the attending veterinarian or by us.

We used Fisher's exact test (Table 1) to compare the total proportion of atretic calves among those born on the farm where pregnancy was diagnosed by early rectal palpation of the dams ( $<42$ days PI), with that among calves born on other farms where early rectal palpation was not practiced. The test covered the entire 2-year period, because the method had been practiced for two consecutive reproductive cycles.

Table 1. Comparisons of proportions of calves born in affected and control herds

\begin{tabular}{lccr}
\hline & $\begin{array}{l}\text { Exposed calves } \\
\text { (early rectal } \\
\text { palpation }+ \text { ) }\end{array}$ & $\begin{array}{l}\text { Non-exposed calves } \\
\text { (early rectal } \\
\text { palpation -) }\end{array}$ & Total \\
\hline Cases (atresia + ) & 47 & 0 & 47 \\
Non-cases (atresia -) & 635 & 800 & 1435 \\
Total & 682 & 800 & 1482 \\
\hline
\end{tabular}


A calf was defined as atretic $(n=47)$ if it did not defecate at all after birth although it received colostrum, and if its condition was confirmed by qualified veterinarians as an atresia case.

A non-case $(n=1435)$ was defined as a calf that defecated normally within a few hours of drinking colostrum.

An exposed calf $(n=682$; calf-at-risk) was defined as a calf born to a dam that had been diagnosed by early rectal palpation.

A "non-exposed calf" ( $\mathrm{n}=800)$ was defined as a calf born to a dam in selected control herds in which early rectal palpation was not practiced. These selected herds were large dairy herds, located at least $20 \mathrm{~km}$ away from the two affected herds, to the north and south of the affected focus. The observation periods of the selected control and affected herds overlapped.

The odds of a calf-at-risk having intestinal atresia were measured by calculating the odds ratio (OR) and the lower and the higher $95 \%$ confidence interval (CI) from a $2 \times 2$ contingency table (Table 1). To enable calculation, 0.5 was added to each value, because one value was zero.

By collecting anamnestic data, we concluded that atretic calves were born about one year after early rectal pregnancy palpation was performed (which was between 35 and 42 days PI). No cases were recorded before the adoption of early pregnancy per rectum palpation PI.

A total of 47 atretic calves $(6.9 \%)$ were recorded, out of 682 calves-at-risk born in both herds over the 2-year period.

An extremely highly significant difference between the affected and the control herds $\left(\mathrm{p}<10^{-4}\right)$ was found, by Fisher's exact test.

The odds of having intestinal atresia were 119.7 times higher for an exposed calf than for a calf born in the control herds (95\% CI; 7.4-1946.3).

On PM two types of intestinal atresia were diagnosed: atresia coli and atresia ilei. The attending veterinarian was unable to specify which type of intestinal defect he saw.

Our investigation indicated that the outbreak of intestinal atresia, seemed to be closely connected with the type of pregnancy test adopted in the two herds. Moreover, the time of appearance - less than one year after the introduction of per rectum palpation of early pregnancy - is in agreement with a similar classical case described in Germany $[2,12]$. It can be deduced that the total contrast between the absence of the defect among the non-exposed calves, on the one hand, and its appearance in the exposed group (those whose their dams were palped per rectum at less than 40 days PI), on the other hand, might indicate that early pregnancy examination per rectum is a major iatrogenic factor leading to intestinal atresia $[2,4]$.

This intestinal atresia outbreak described in the present note involved a much higher incidence than had been reported in the literature previously $[2,3,5-8,10,13-16]$ and showed features of an epidemic outburst, since the affected calves were born throughout a relatively short period of time. So far, such an outbreak can only be attributed to a genetic $[9,13]$ or iatrogenic cause $[2,12]$. Under these circumstances, the sporadic "spontaneous" form seems to be of very low probability. As to the genetic background of these episodes, it has been proven, by crossexamination of the Artificial Inseminations Center's rostrer (with the collaboration of the Israeli Cattle Breeders' Association) that covered the period between 1998 and 2000, that a very small number of selected bulls were used to fertilize our dairy cows. The sole difference which was found between the two affected farms and the control ones, concerned the change in the method to diagnose pregnancy. Thus, the iatrogenic factor remains as the most probable cause for the above described episode. Moreover, no new cases of intestinal atresia were recorded one year after the palpation method of diagnosing early pregnancy was abandoned.

Thurmond and Picaso [20] identified two early distinguishable sub-periods regarding the risk for fetal loss. They calculated that the first sub-period, 28-35 days PI, was much less risky than the second one, 35-42 days (OR 2 vs. 30 respectively). In our study, pregnancy had been examined during the much higher sub-period of much higher risk (between 36 and 42 days PI).

Louw and Bernard [11] have suggested that interruption of the mesenteric blood supply during manipulation of the vesicle might cause some injuries.

Palpating the amnion or the fetal membranes may injure the fetus and could become a significant iatrogenic cause of fetal losses [1, 4, 15, 20-22].

In one critical review, Constable et al. [3] stated that palpation per rectum for early pregnancy diagnosis is not a prerequisite for atresia coli but that it could predispose the embryo to develop the condition. Overall, when the early pregnancy diagnosis by amniotic vesicle palpation is applied, intestinal atresia is associated with it in a frequency-dependent manner. Constable et al. [3] proposed that atresia coli occurs in cattle as a secondary effect of vascular insufficiency of the developing spiral colon, and that the Holstein-Friesian fetus is predisposed to atresia coli because of the faster growth rate and greater size of the colon [3].

In another retrospective study [2], 28 of 524 calves $(5.2 \%)$ whose dams had been palpated up to 40 days PI were born with intestinal atresia, whereas none of 995 calves whose dams had been palpated later than 40 days PI suffered from intestinal atresia. The same authors $[2,12]$ conducted an experimental study, in which the amniotic vesicle was palpated once a day between 32 and 41 days of gestation, with the result that 7 of 12 calves were born with intestinal atresia. This study provides the most convincing data connecting early pregnancy diagnosis by palpation with intestinal atresia.

\section{REFERENCES}

1. Abbitt, B., Bail, L., Kitto, G.P., Sitzman, C.G., Wilgenburg, B., Raim, L.W. and Seidel, G.E. Jr. 1978. J. Am. Vet. Med. Assoc. 173: 973-977.

2. Benda, A., Hasse, H., Willer, S., Berschneider, F., Muller, W. 
and Mauke, A. 1978. Monatsh. Vet. Med. 33: 683-687.

3. Constable, P.D., Shanks, R.D., Huhn, J. and Morin, D.E. 1997. Theriogenology 48: 775-790.

4. Franco, O.J., Thatcher, M.-J., Shille, V.M. and Thatcher, W.W. 1987. Theriogenology 27: 631-644.

5. Geringer, H. 1994. Roczniki Naukowe Zootechniki 21: 19-24.

6. Herschler, M.S., Fechheimer, N.S. and Glimore, L.O. 1962. J. Dairy Sci. 45: 1493-1499.

7. Hoffsis, G.F. and Bruner, R.R Jr. 1977. J. Am.Vet. Med. Assoc. 171: 433-434.

8. Hunter, A.G. 1974. Vet. Rec. 94: 170.

9. Jubb, K.U.F. and Kennedy, P.C. In: Pathology of Domestic Animals. Academic Press, New York-London.

10. Leipold, H.W., Dennis, S.M. and Huston, K. 1972. Adv. Vet. Sci. 16: 103-150.

11. Louw, J.H. and Bernard, C.N. 1955. Lancet 2: 1065-1067.

12. Ness, H., Leopold, G. and Muller, W. 1982. Monatsh. Vet. Med. 37: 89-92.

13. Nihleen, B. and Eriksson, K. 1958. NordVet. Med. 10:113-
127.

14. Ondraskova, J., Slapnicka, J., Farka, Z., Kobylka, V. and Kralova, A. 1991. Xvgenetic dnyCeske Budejovicie 116: 18.

15. Paisley, G.L., Mickelsen, W.D. and Frost, O.L. 1978. Theriogenology 9: 481-491.

16. Preister, W.A., Glass, A.G. and Waggoner, N.S. 1970. Am. J. Vet. Res. 31: 1871-1879.

17. Rosenberger, G. 1970. p. 338. Krankheiten des Rindes. Verlag Paul Parey, Berlin.

18. Skewes, A.R. 1962. Vet. Med. 57: 133-134.

19. Steenhaut, M., DeMoor, A., Verschooten, F. and Demest, P. 1976. Vet. Rec. 98: 131-133.

20. Thurmond, M.C. and Picaso, J.P. 1993. J. Am. Vet. Med. Ass. 203: $432-435$.

21. Vaillancourt, D., Bierschwal, C.J., Ogwu, D., Elmore, R.G., Martin, C.E., Sharp, A.J. and Youngqist, R.S. 1979. J. Am. Vet. Med. Ass. 175: 466-468.

22. White, M. E., LaFaunce, N. and Mohammed, H.O. 1989. Can. Vet. J. 30: 147-149. 